\title{
Correlates of Satisfaction With Life for People Who Identify as Transgender and Sexual Minority
}

\author{
Christopher C. Bober \\ Michigan School of Professional Psychology \\ Kristen L. Suing \\ Michigan School of Professional Psychology \\ Dustin K. Shepler \\ Michigan School of Professional Psychology
}

\begin{abstract}
Researchers have focused on understanding factors such as resiliency, medical concerns, and coping skills in the lives of transgender and gender-nonconforming people. However, little research has examined how transgender and gender-nonconforming people cognitively evaluate their own lives. Furthermore, many people who identify as transgender or gendernonconforming also report a sexual minority identity status. In this study, we sought to understand how aspects of sexual self-concept (i.e., sexual esteem and sexual anxiety), internalized homonegativity, and level of outness about sexual identity correlated to selfappraisals of satisfaction with life (SWL) in a sample of transgender and gendernonconforming people who identified as sexual minorities. Participants were recruited at a lesbian, gay, bisexual, transgender Pride festival and completed a paper-pencil survey. Results indicated that there was a positive relationship between SWL and sexual esteem and a negative relationship between SWL and sexual anxiety. The relationship between SWL and internalized homonegativity approached significance while level of outness did not appear to be related to SWL. Implications for research and clinical practice are discussed.
\end{abstract}

Keywords: trans*, transgender, genderqueer, satisfaction with life, life satisfaction, subjective wellbeing, $L G B T$

\section{Introduction}

Numerous recently published studies have improved the understanding of important issues relevant to transgender and gender-nonconforming people (hereafter collectively referred to as transgender people). Authors have focused on medical concerns (e.g., Donald \& Ehrenfeld, 2015), the impact of violence (DiFulvio, 2015; Peitzmeier et al., 2015), the importance of resiliency and effective coping skills (Bariola et al., 2015; Breslow et al., 2015), and positive effects of social support (Graham et al., 2014; Pflum, Testa, Balsam, Goldblum, \& Bongar, 2015) for transgender people. Despite these advances in our understanding, there is still a need for research that explores how transgender people cognitively evaluate their own lives.

According to a report from the National Center for Transgender Equality, over 60\% of transgender people identify as nonheterosexual and are consequently managing at least two stigmatized identities (Grant et al., 2011). Individuals with multiple layers of oppression exhibit higher levels of 
psychological distress (Diaz, Ayala, Bein, Henne, \& Marin, 2001), and greater difficulty connecting to a community when compared to the general population (Greene, 1994). Given these assertions, it is important to examine how aspects of both gender and sexual identity impact perceptions of satisfaction with life (SWL) for members of the transgender community. Recognizing that transgender people who identify as heterosexual or "straight" may differ in important ways from transgender people who identify as sexual minorities, we limit our focus to dual (gender and sexual) minority persons. Specifically, we sought to explore how factors of sexual self-concept (SSC), internalized homonegativity (IH), and level of outness (LO; i.e., in regards to sexual identity) correlate with SWL for members of the transgender community who also identify as sexual minorities.

We posit that the attitudes and perceptions people have of themselves as a sexual beings, or their SSC, have implications for their overall perception of SWL. This position is grounded in the importance people place on sexuality and sex in the United States. Additionally, how people manage their sexual identity and conflicting, often stigmatizing, messages about their gender and sexual identities has implications for perceptions of overall SWL. More specifically, in cisgendered samples (i.e., samples composed of individuals whose "gender identity aligns with ... the sex assigned to them at birth"; Human Rights Campaign, 2016, para. 7), not disclosing sexual identity and internalizing negative attitudes toward their sexual identity have both been linked to poor mental health and identity uncertainty (e.g., Frost \& Meyer, 2009; King \& Smith, 2004).

We sought to add to the body of literature by examining SSC in relation to SWL for the transgender population. The SSC factors we included in this study are sexual anxiety (SA) and sexual esteem (SE). These two constructs were chosen over other constructs (e.g., sexual motivation) due to their inclusion across most models of SSC (Deutsch, 2012). Notably, no similar research examining the possible relationship between the identified factors and SWL for people outside of the gender binary could be located.

Importantly, IH and LO, both of which are related to SCC in meaningful ways, have intrapersonal and interpersonal aspects, which likely have significant impacts on SWL. For instance, while individuals' processes of coming out may include a time when they are privately aware of their sexual identity, LO is typically associated with interpersonal contexts (e.g., work, school, family, friends). These variables represent the real world complexity seen in the psychotherapy office and have high clinical utility. We suggest that because of this complexity, our variables are generalizable, systemic, and interconnected.

This study contributes to both the larger SWL research as well as the body of research on transgender issues. Findings may be useful for mental health professionals as they prepare to develop trans-affirmative interventions and in acknowledging the differences between gender identity and sexual identity (Carroll \& Gilroy, 2002). For example, therapists may find this information helpful when working with clients who seek to understand their experience of evolving two stigmatized identities. Clients may benefit from a dialogue about how they want to express these identities in their personal and professional relationships, specifically the impact of changes in gender roles and attractional status. This study is particularly relevant for those individuals who identify as nonheterosexual and transgender and want assistance understanding the link between SSC and SWL. Consistent with the Guidelines for Psychological Practice With Transgender and Gender Nonconforming People (American Psychological Association, 2015) and the World Professional Association for Transgender Health's Standards of Care (Coleman et al., 2012), we posit 
that exploration of SWL correlates will help clinicians understand the intersectionality of transgender identities and communities become more knowledgeable about transgender individuals.

\section{Gender Identity and Sexual Orientation}

Current research explores the intersectionality of gender identity and sexual orientation for members of the transgender community (Meier \& Labuski, 2013). Sexual orientation is a facet of identity development that can change over one's lifetime (Bockting, Benner, \& Coleman, 2009). Due to changes in gender expression and social sexual roles, some transgender people may experience a shift in their sexual orientation during the gender affirmation process (Mizock \& Hopwood, 2016). This change in experience of sexual orientation may involve a shift from a nonstigmatized identity to a stigmatized one. For others in the transgender community, their sexual orientation has always been experienced as stigmatized. Some transgender individuals reject a connection between gender and sexual orientation, because fixed labels do not typically represent the dynamic nature of gender identities (Lenning \& Buist, 2013). Conversely, some identify as "queer" as to eschew the constraints of traditional sexual orientation identifiers based on gender or assigned sex (Mizock \& Hopwood, 2016).

Research also indicates that external misperceptions of sexual orientation and gender identity impact transgender people. Nonbinary identities continue to threaten traditional models of sexual orientation, gender, and power. Gender identity and sexual orientation can be conflated by others, resulting in transphobia and homophobia (Mizock \& Lewis, 2008). This conflation can lead to discrimination which can negatively impact quality of life (QOL; Grant et al., 2011). It can also lead to "homophobic transphobia" that, when internalized, can affect an individual's willingness to come out to a supportive community (Mizock \& Hopwood, 2016, p. 100).

\section{Satisfaction With Life}

SWL is defined as the level of contentedness people have when they evaluate their lives (Diener, Emmons, Larsen, \& Griffin, 1985). This evaluation stems from self-defined standards, values, and social comparison (Diener \& Ryan, 2009). Research has demonstrated relationships between SWL and personality (DeNeve \& Cooper, 1998), positive emotions (Seligman, 2002), age (Palgi \& Schmotkin, 2010), important life events (Shahar, 2007), and authenticity (Peterson, Park, \& Seligman, 2005). SWL has been shown to have a relationship with subjective well-being (Diener \& Ryan, 2009) and is typically defined as a factor of the broader SWB category. Furthermore, SWL has been shown to have independence from other variables that impact SWB, such as positive emotions and lack of negative emotions (Diener, Oishi, \& Lucas, 2003). In this way, SWL has been viewed as a way to understand how people cognitively evaluate their lives. Multiple decades of research have demonstrated the usefulness of measuring SWL to understand people's perceptions of their lives. To date, there has been little empirical research on how members of the transgender community perceive their SWL. However, there are a number of studies that examine a similar broad concept, quality of life (QOL).

QOL is typically defined as having a high convergence with SWB and SWL; however, research has yet to form a consensus on how to operationally define it (Miller, Hyder, Zinkiewicz, Droste, \& Harris, 2014). Lawton (1991) highlights its complexity, stating, "Quality of life is the multidimensional evaluation, by both intrapersonal and social-normative criteria, of the personenvironment system of the individual" (p. 6). Typically research on QOL for the transgender 
community has often focused on health related variables related to sexual reassignment surgery or hormone replacement therapy. Additionally, QOL research often relies on the Short Form (36) Health Survey developed by the RAND Corporation for the Medical Outcomes Study (Hays, Sherbourne \& Mazel, 1995). This instrument was originally developed to measure the efficacy of treatments for longstanding diseases by examining participants' perceptions of vitality, physical functioning, bodily pain, general health, emotional role functioning, physical role functioning, social role functioning, and mental health (Hays et al., 1995; Ware \& Sherbourne, 1992). While use of this instrument has insured replicability and has been helpful in providing insight into QOL concerns, it has not adequately accounted for transgender individual's cognitive perceptions of SWL.

One factor influencing SWL is the rate of discrimination faced by transgender individuals. Lesbian, gay, bisexual, transgender (LGBT) individuals are twice as likely to report suicidal ideation or make a suicide attempt than the general population (Haas et al., 2010; King et al., 2008) and discrimination has been linked to increases in suicidal ideation (Sutter \& Perrin, 2016). Sixty-three percent of transgender individuals have experienced a serious act of discrimination (i.e., loss of job due to bias, eviction due to bias, sexual assault, and/or loss of relationship due to gender/sexual identity status; Grant et al., 2011). Transgender people also face discrimination in their romantic relationships, with a significant number of transgender people reporting that they have experienced some loss of relationship due to stigma regarding their sexual or gender identity (Grant et al., 2011). Therefore, it is likely that frequent acts of discrimination reduce QOL and SWL for transgender individuals.

In a study using a measure of QOL (i.e., the SF-36), transmen (i.e., those with male gender identities but assigned female sex at birth) reported significantly lower QOL in regard to mental health than cisgendered men in the United States (Newfield, Hart, Dibble, \& Kohler, 2006). Transgender individuals who received hormone replacement therapy showed improvements in their QOL when compared to participants who had not undergone treatment (Gorin-Lazard et al., 2012; Newfield et al., 2006). Similarly, researchers have observed greater QOL for individuals who identify as transsexual following sexual reassignment surgery or facial reconstruction (Ainsworth \& Spiegel, 2010; Wierckx et al., 2011). After at least 6 months following sexual reassignment surgery, transwomen showed higher levels of functioning in regards to physical, emotional, psychological, and social values (Weyers, Monstrey, Hoebeke, De Cuypere, \& Gerris, 2008).

However, follow-up studies suggest there are remaining concerns for some transgender individuals regarding QOL. Sexual functioning (e.g., arousal, lubrication, and pain) was lower for transwomen (i.e., those with feminine gender identities but assigned male sex at birth) compared to cisgendered women (Weyers et al., 2008). Motmans, Meier, Ponnet, and T'Sjoen (2012) reported that although transwomen did not differ from Dutch cisgendered women, transmen scored significantly lower on measures of mental health than Dutch cisgendered men. Transwomen fared better than transmen in regards to physical functioning and general health. Although transwomen reported higher initial levels of bodily pain, over time, transmen reportedly experienced greater role limitations due to physical health problems (Motmans et al., 2012). Finally, when socioeconomic status (including level of education, employment status, income level, and relationship status) was considered, Motmans et al. (2012) reported that transpeople reported lower QOL than cisgendered people. While limited, the available research regarding QOL is comparatively greater than that examining SWL in the transgender community. 
In one of the few studies that examined SWL in a sample of transgender adults, Erich, Tittsworth, Dykes, and Cabuses (2008) found that transgender people generally had good family relationships and levels of life satisfaction, "despite potential difficulties in areas related to self-esteem" (p. 419). Furthermore, they found that perceptions of healthy family relationships were positively correlated with perceptions of SWL and self-esteem (Erich et al., 2008). Similar results have been reported for transgender teens. In Simons, Schrager, Clark, Belzer, and Olsen (2013), transgender adolescents who perceived their parents as emotionally supportive reported greater SWL, less stress due to their identities, and fewer signs of depression than transgender adolescents who reported lower levels of parental support. The authors concluded that when parents are supportive of their transgender children, the children have a higher reported life satisfaction and that this support guards the children from the potential onset of depression. While social support appears to mitigate the effects of discrimination on SWL, we could not locate any studies that examined the relationship between LO, SA, SE, IH, and SWL in the transgender community.

\section{Sexual Self-Concept}

SSC has been identified in the literature as an "active, dynamic structure that forms by organizing perceptions of personal sexual qualities into a cohesive, internalized construct" (Deutsch, Hoffman, \& Wilcox, 2014, p. 2). As described by Deutsch (2012), "The sexual self has both intrapersonal and interpersonal dimensions [and] requires understanding and evaluation of the self as both a sexual individual alone as well as in the context of a sexual experience with another individual" (p. 5). SCC is a subjective perception and evaluation of one's self as a sexual individual in relation to another/others, in this way, SCC is similar to SWL in that is has intrapersonal and social-normative evaluations, such as social comparison and perceptions of sexual socialization (Deutsch et al., 2014).

The research examining SSC divides into two categories. One area of research focuses on the creation of measurement instruments (e.g., O'Sullivan, Meyer-Bahlberg, \& McKeague, 2006; Snell, 1998; Vickberg \& Deaux, 2005) the other area explores how SCC relates to other aspects of sexuality, such as sexual behavior (Breakwell \& Millward, 1997), contraceptive use (Winter, 1988), sexual selfefficacy (Rostosky, Dekhtyar, Cupp, \& Anderman, 2008), sexual socialization (Aubrey, 2007), or sexual emotionality and gender roles (Deutsch et al., 2014; Garcia, 1999). Overall, research in this area has not led to the formation of a consensus on how to define SSC or measure it (Deutsch, 2012).

Despite the moderate amount of literature that examines the relationship of SSC with other variables, or addresses scale development, it appears no research has examined how SSC may be related to SWL in transgender persons. In this study, we focus on two aspects of SSC that have been recognized as important factors of SSC across multiple theoretical models (Deutsch, 2012): SA and SE. While some research has examined the sexual health of transgender people (e.g., Bauer \& Hammond, 2015), we could not find any research on SA or SE focused on transgender people.

\section{Sexual Esteem}

SE has been defined in different ways. Some definitions of SE are broad (e.g., "self-esteem towards one's sexuality"; Hensel, Fortenberry, O’Sullivan, \& Orr, 2011, p. 4). Other definitions suggest multidimensionality (e.g., "a generalized tendency to positively evaluate one's own capacity to engage in healthy sexual behaviors and to experience one's sexuality in a satisfying and enjoyable way"; Snell, 1998, p. 2). Overall, the research suggests that a person who has high sexual self-esteem has confidence in their sexuality and is fulfilled by their sexual abilities (Snell, Fisher, \& Walters, 
1993). SE has a positive relationship to sexual satisfaction (Ménard \& Offman, 2007; Zeanah \& Schwarz, 1996) and is correlated with a healthy sex life and interpersonal functioning (Giordano \& Rush, 2010; Mayers, Heller, \& Heller, 2003).

\section{Sexual Anxiety}

A consensus on the definition of SA has also not been reached (Deutsch, 2012). However, most definitions suggest that SA is the amount of tension, discomfort, and anxiety a person reports about the sexual aspects of their life (Snell et al., 1993). Some definitions suggest the inclusion of the intrapersonal aspects of SA, including feeling anxious about imagined sexual activities (Hensel et al., 2011) and sexual life in the future (Rostosky et al., 2008). Other definitions point to the interpersonal nature of SA, such as when an individual thinks they have failed to comply with "perceived normative sexual standards" (Deutsch, 2012, p. 15) or when they feel anxiety in a sexual situation (Hensel et al., 2011).

Experimental studies that examined SA, sexual arousal, and enjoyment showed mixed results (van den Hout \& Barlow, 2000). One study demonstrated that SA interfered with women's sexual arousal, but only in conditions when it was paired with tasks that were considered distracting (Elliott \& O'Donohue, 1997). Another study showed anxiety causing situations decrease women's subjective sexual arousal yet increase their physiological arousal (Palace \& Gorzalka, 1990). However, lower sexual pleasure is reported when SA is high (Birnbaum, Reis, Mikulincer, Gillath \& Orpaz, 2006).

\section{Internalized Homonegativity}

The terms internalized homophobia and internalized homonegativity have often been used interchangeably and have been discussed as the internalization of anti-gay attitudes found in society (Herek, 2004), or the "self-directed prejudice by lesbian, gay, or bisexual individuals as they take in or internalize negative attitudes and assumptions about their non-heterosexual" identity (Kappler, Hancock, \& Plante, 2013, p. 807). Several studies have linked internalized homophobia to negative mental health for LGB men and women; however, no previous research examining the link between IH and SE, SA, or SWL could be located. The literature on IH and outness appears to suggest that IH may be negatively related to outness for some, but not all sexual minority people. In the absence of any identifiable research on IH for people who identify as both transgender and a sexual minority, it is unknown how well the extant literature on IH applies to transgender people. However, a review of the research on IH completed with primarily cisgender LGB people may provide some insight into the potential impact of IH for transgender people.

Bryce (2013) reported that IH (as well as restrictive emotionality) was negatively related to relationship satisfaction for gay men, while Edwards and Sylaska (2013) reported that IH was related to the perpetration of physical and sexual partner violence in LGBTQ college students. Morrison (2012) reported that IH was more strongly related to depression in lesbian women than in gay men, and Fingerhut, Peplau, and Ghavami (2005) have suggested that IH was related to how sexual minority women manage their identities. Wilkerson, Smolenski, Brady, and Rosser (2012) found that increased religiosity was associated with increased homonegativity and decreased outness for evangelical protestant Christian (but not for Catholic or Mainline Protestant) men. IH has been found to relate to disclosing a sexual minority identity with bisexual men having the lowest rate of disclosure and highest rate of $\mathrm{IH}$, and lesbian women having the highest rate of coming out to family and lowest rate of IH (Costa, Pereira, \& Leal, 2013). While the relationship between IH and 
relationship satisfaction, emotional well-being, and comfort with sexual identity appears clear, how IH impacts health behavior is less clear. Specifically, while some have reported that IH has been linked to decreased HIV testing for men who have sex with men (Andrinopoulos et al., 2015) and associated with riskier sexual behaviors, such as unprotected anal intercourse among gay and bisexual men (Ross, Kajubi, Mandel, McFarland, \& Raymond, 2013), others have questioned the meaningfulness and strength of the relationship between IH and increase in risky sexual behaviors (Smolenski, Stigler, Ross, \& Rosser, 2011) or have reported contradictory findings (Jacobs et al., 2010).

\section{Level of Outness}

"Coming out" is defined as the disclosure of one's sexual or gender identity to others (Mohr \& Fassinger, 2000). The level of one's outness, then, can be conceptualized as the degree to which one has come out to others in their daily life. The LO may vary in different facets of their life (e.g. family, friends, coworkers, religious leaders). In other words, an individual may be out in some areas while concealing portions of their identity in other areas. Indeed, concealing their identity may be used as a coping mechanism to protect them from stigmatization and prejudice (Safren \& Pantalone, 2006). Notably, coming out in controlling environments (environments that do not allow individuals to make decisions autonomously) does not correlate with similar benefits (Legate, Ryan, \& Weinstein, 2012). Others (Strain \& Shuff, 2010) reported that being out as transgender is correlated with fewer depression and anxiety symptoms and with higher self-esteem. However, that study did not include members of the genderqueer (i.e., those who "reject notions of static categories of gender and embrace a fluidity of gender identity..."; Human Rights Campaign, 2016, para. 17) population or examine SWL. Additionally, while previously discussed research suggests that family support may be an important contributing variable to SWL (Erich et al., 2008; Simons et al., 2013), no longitudinal studies examining SWL and the coming out process could be located.

\section{Hypotheses}

Based on the extant literature, we hypothesized that SE and being "out" would be positively correlated with SWL while SA and IH would be negatively correlated with SWL.

\section{Method}

\section{Procedure}

After obtaining approval from the institutional review board at the Michigan School of Professional Psychology, attendees who passed our booth at an LGBT Pride festival in the Detroit metro area were invited to take part in the study. Transgender people in this location face many difficulties including few medical professionals trained to work with transgender identities, lack of insurance coverage for medical care and laws requiring sex surgery to get gender marker changes on government identification. However, there are also LGBT resource centers nearby which offer supportive environments. For more details on the transgender culture in this area, see Graham et al. (2014) who describe the narrative of transitioning for Black transgender women in Detroit. Attendees who agreed to participate in the survey were given a clipboard and pen to complete an informed consent form and the paper-based survey. The survey was composed of demographic items and five standardized scales. Participation took approximately $15 \mathrm{~min}$. to complete the survey. 


\section{Participants}

Transgender participants were selected out of the larger sexual and gender minority community based on their identified gender (i.e., transgender, genderqueer, genderfluid). Participants who identified as heterosexual or "straight" were excluded because one of the variables under investigation, IH, requires that an individual identify as a sexual minority for the construct to be relevant and meaningful and to increase internal validity of the results. In other words, only data from dual minority participants was retained for analysis.

Thirty-six transgender individuals participated in the study. However, four participants did not respond to at least half of the questions on each scale and one participant did not report a sexual identity. Their data was subsequently dropped from analysis. Therefore, data from 31 participants were included for analysis. Mean replacement was used to handle unanswered questions if the participant responded to at least half of the items on within each subscale. Participants selfidentified as transgender $(n=12)$, genderqueer $(n=16)$, or genderfluid $(n=3)$. Those in the sample identified as gay $(n=5)$, lesbian $(n=5)$, bisexual $(n=5)$, pansexual $(n=5)$, queer $(n=7)$, or other nonheterosexual identity $(n=4)$. Participants identified as White/Caucasian $(n=22)$, Black/African American $(n=1)$, Hispanic $(n=1)$, Asian American/Pacific Islander $(n=1)$, Middle Eastern $(n=1)$, bi-/multiracial $(n=4)$, or other $(n=1)$. They ranged in age from 18 to 53 years old $(M=27.03, S D=$ 10.55).

\section{Instruments}

\section{Satisfaction With Life Scale}

The SWL Scale (Diener et al., 1985) included 5 Likert-type items used to measure global life satisfaction. For the purposes of this study, SWL is defined as the "judgment of how satisfied people are with their present state of affairs ... based on a comparison with a standard which each individual sets for self' (p. 71). Participants responded to the SWL scale using a 7-point scale ranging from strongly disagree to strongly agree. Individual item responses were aggregated into an overall scale score. The scale ranged from 5 to 35. Participants' scores on SWL ranged from 6 to 32 with a mean score of $24.64(S D=6.29)$. The internal reliability for the SWL scale was acceptable $(\alpha=$ $.832)$.

\section{Sexual Esteem and Sexual Anxiety Scales}

Rostosky and colleagues' (2008) modified versions of the Sexual Esteem (eight items) and Sexual Anxiety (eight items) subscales of Snell's (1998) Multidimensional Sexual Self-Concept Questionnaire were used to measure the noted aspects of SSC. Snell (1998) defines SE as "a generalized tendency to positively evaluate one's own capacity to engage in healthy sexual behaviors and to experience one's sexuality in a satisfying and enjoyable way" (p. 1) whereas SA is the "tendency to feel tension, discomfort and anxiety about the sexual aspects of one's life" (p. 1). Participants respond to the SA and SE subscales using a 5-point Likert-type scale ranging from very uncharacteristic of me to very characteristic of me, with some items being reverse scored. Scores on each subscale can range from 0 to 40, where higher scores indicated increased endorsement of the construct (i.e., higher scores meant more SE and more SA on the respective scales). Participants' scores ranged from 8 to 40 on the SA scale and from 16 to 40 on the SE scale, suggesting that ceiling effects may have been a concern on both scales. Internal reliability for the SE scale was acceptable $(\alpha$ $=.915)$ and participants reported a mean $\mathrm{SE}$ score of $31.864(S D=7.04)$. Internal reliability for the SA scale was acceptable $(\alpha=.861)$ and participants reported a mean SA score of $16.95(S D=7.55)$. 


\section{Internalized Homophobia (IH) Scale}

The Internalized Homophobia Scale (Wagner, 1998) is a 20 -item scale that was "developed for use with gay men and intended to measure the extent to which negative attitudes, and beliefs about homosexuality are internalized and integrated into one's self-image and identity as gay" (p. 371). Wording was broadened to be inclusive of various gender identities and sexual identities. Specifically, items were restructured with gender-neutral language and "bisexuality" was added to items as appropriate. For instance, "Male homosexuality is a natural expression of sexuality in human males" (Wagner, 1998, p. 372) was changed to "Homosexuality/bisexuality is a natural expression of human sexuality." These changes allow for a wide variety of individuals to respond to the concepts identified by Wagner without necessitating specific a gender identity and sexual identity. Participants respond to the IH scale using 5-point Likert-type scales ranging from strongly disagree to strongly agree. Scores on the IH scale can range from 20 to 100. On the IH scale, participants' scores ranged from 20 to 61 with a mean score of 47.07 ( $S D=11.01)$. Internal reliability for the IH scale was acceptable $(\alpha=.887)$.

\section{Outness Inventory (OI)}

The OI is an 11-item scale designed to assess the degree to which LGB individuals are open about their sexual identity (level of "outness"). Responses on the OI items indicate the degree to which the respondent's sexual identity is known by and openly discussed with various types of individuals (e.g., mother, work peers; Mohr \& Fassinger, 2000). The participants responded using a 7-point Likerttype scale ranging from the person definitely does not know about your sexual orientation status to the person definitely knows about your sexual orientation status, and it is openly talked about. Scores on the OI could range from 11 to 77 and participants' observed OI scores ranged from 17 to 77 with a mean score of $47.07(S D=18.26)$. Internal reliability for the scale was acceptable $(\alpha=.857)$.

\section{Results}

\section{Preliminary Analysis}

While those who identify as genderqueer are considered members of the transgender community, it was important to consider whether those who identified as genderqueer might have, for some reason we had not considered, responded differently to the survey than those who identified as transgender. Subsequently, an independent samples $t$-test was conducted to determine whether genderqueer individuals varied significantly from people who identified as transgender on the variables of interest. Levene's test indicated equal variances could be assumed on all analyses. Results indicated no significant differences between groups who identify as transgender and genderqueer on any of the measured factors. The transgender and genderqueer participants were therefore collapsed into one larger sample for further analysis.

\section{Main Analysis}

To investigate whether SWL, SA, SE, IH, or outness were related, a two-tailed Pearson bivariate correlation analysis was conducted. The hypothesis that SWL would be significantly and inversely related to $\mathrm{SA}, \mathrm{IH}$, and LO, while significantly and positively related to SE was tested. Despite low statistical power $(1-B=0.13)$, significant results were observed. Using Cohen's (1988) classification system, there was a strong positive relationship between SWL and SE $(r=.760, p \leq .000)$ and a strong negative relationship between SA and SWL $(r=-.485, p=.008)$. The relationship between IH and SWL approached significance (and with a larger sample would likely have proven significant due 
to increased power associated with larger sample size; $r=-.362, p=.054)$. There was a strong negative correlation between SE and SA $(r=-.757, p \leq .000)$. Similarly, SE and IH were strongly and negatively correlated $(r=-.610, p \leq .001)$. SA and IH were significantly positively correlated $(r=$ $.706, p \leq .000)$. Results indicate that LO was not significantly related with any of the other variables (see Table 1).

Table 1. Correlates of Satisfaction With Life

\begin{tabular}{lcccc}
\hline & 1 & 2 & 3 & 4 \\
\hline 1. SWL & - & & & \\
2. SE & $.760^{* *}$ & & & \\
3. SA & $-.485^{* *}$ & $-.757^{* *}$ & & \\
4. IH & -.362 & $-.610^{* *}$ & $.706^{* *}$ & \\
5. LO & .074 & .075 & .043 & -.233 \\
\hline
\end{tabular}

Note. $\mathrm{SWL}$ = satisfaction with life; $\mathrm{SE}$ = sexual esteem; $\mathrm{SA}=$ sexual anxiety; $\mathrm{IH}$ = internalized homonegativity; $\mathrm{LO}=$ level of outness.

$* * p=.01$.

\section{Discussion}

Based on the sample obtained in a large national study, only about one in five transgender people seem to identify as straight or heterosexual (Grant et al., 2011); however, researchers have tended to ignore the potential for people who are transgender to have to manage two stigmatized identities while focusing primarily on gender identity. In this study, we sought to increase internal validity by decreasing the possibility that some participants may be managing two stigmatized identities while others manage one. Subsequently, only those who identified as transgender and sexual minorities were included in the sample. While this decision limits the generalization of findings to the minority of people who identify as transgender and heterosexual, it increases the relevance of the findings for those who identify as both transgender and sexual minority.

We hypothesized that SWL would be positively correlated with SE and negatively correlated with SA. Indeed, the results indicate that SWL was positively correlated with SE and inversely correlated with SA. This finding suggests that the way transgender people who identify as sexual minorities feel about their ability to handle sexual encounters is related to their overall SWL. This finding is consistent with other recent research suggesting that a similar relationship has been observed for cisgender LGB people and heterosexual people in the United States (Shepler, Johnson, \& Ho, 2015). We suggest that this similarity across gender and sexual identities speaks to a broader understanding of how sexuality is linked to SWL.

We also hypothesized that SA and IH would be negatively correlated with SWL. The results of the study supported these hypotheses. In other words, when individuals reported higher levels of worry about aspects of their sexual lives or reported greater internalized sexual stigma, their SWL decreased. This finding bolsters the possibility that when individuals internalize negative attitudes regarding their sexual identity, their ability to reflect positively on their sexual lives decreases; however, because this study utilized a correlational (as compared to causal) design, inferences are limited and future study is necessary to explore this potential phenomenon.

Although LO is correlated with SWL for members of the LGB community (Garnets \& Kimmel, 1993; Jordan \& Deluty, 2000), contrary to our expectations, a similar relationship was not observed in our 
sample of people who identify as dual minorities based on sexual and gender identity. This may be due to potential covariates that were not measured within the context of this study including the general lack of supportive services (Beemyn, 2003), the stigma associated with identifying as transgender (Gagné, Tewksbury, \& McGaughey, 1997) and/or the patterns of discrimination and violence against transgender people (Lombardi, Wilchins, Priesing, \& Malouf, 2002). Moreover, disclosing of sexual minority status may be less important to people who identify as transgender sexual minorities than people who identify as cisgendered sexual minorities. While society has become more accepting of sexual minorities, this does not necessarily include acceptance of transgender people. Indeed, while same-sex marriage is now legal and this marks progress in the acceptance of people who are LGB, similar legislative gains have not been realized for people who are transgender. Furthermore, in our study, the outness and IH scales that were employed were designed specifically for use in regard to sexual identity.

While it is important to consider how outness regarding gender identity and internalized transphobia relate to SWL, our study did not consider these variables due to limitations imposed based on the availability of appropriate instruments. There is currently an unmet need to develop methods of measuring these constructs. Developing appropriate measures would allow for more careful consideration of the intersection between sexual and transgender identity. While participants in the sample were of various transgender identities, sexual minority identities, ages, and racial/ethnic backgrounds, our findings are limited by sample size and geographical region. Participants were recruited at a local pride event and may have felt more positively about aspects of their identities than individuals who opt to not attend such events. Subsequently, this participant characteristic and the relatively supportive, welcoming environment in which they participated may have impacted response tendencies (e.g., possible inflated reports of SE or atypically low levels of IH). Furthermore, participants were recruited in an urban environment in the United States. The results may have limited generalizability to those people who dual identify as transgender and as a sexual minority and who live in another country or a rural area. Future research would benefit from seeking to replicate these findings using a broader community-based sample to increase generalizability and external validity.

Additionally, individuals were not asked to describe their current stage of gender transition. This is a limitation given that transgender individuals who have undergone sex reassignment surgery have been found to increase QOL (Gorin-Lazard et al., 2012; Newfield et al., 2006). It is possible that transgender individuals are only comparable to genderfluid and genderqueer individuals at particular stages of transition. Therefore, additional research is warranted to identify whether stages of transition significantly alter factors that contribute to SWL.

Despite these limitations, our research has social relevance and several important implications for a broad array of mental health professionals, health educators, policy makers, and other advocates. First, the extant literature on marginalized gender identities has traditionally focused on pathology, the experience of being marginalized, and the process of transitioning. Like others, transgender individuals have a complex intersection of identities that, include gender, sexual identity, ethnicity, class, and more (Warner, 2008). Furthermore, transgender people often hold these multiple identities in a social context that includes facing stigma, discrimination, prejudice, and violence (Grant et al., 2011). Research suggests these social factors can create significant distress for transgender people (Coleman et al., 2012). However, these negative social factors do not necessarily lead to distress as some transgender individuals report significant resiliency and strength when faced with these challenges (Singh, 2013). 
Our study, while considering the social context and realities faced by the transgender community, alternatively focuses on those factors that contribute to SWL for this group of people. While outness did not correlate to SWL for transgender people in our sample, transgender people have had to manage the public reactions regarding the transitioning of transgender celebrities (e.g., Caitlyn Jenner, Chaz Bono, Laverne Cox). This further highlights the importance of research related to the transgender community as what has been portrayed as important about the transgender experience by popular media does not appear to reflect factors that are actually important to SWL for transgender people. Having this understanding may help direct therapists away from focusing on irrelevant or tangential concerns and instead focusing on factors that contribute to SWL for their clients.

Secondly, the Guidelines for Psychological Practice With Transgender and Gender Nonconforming People (American Psychological Association, 2015) suggest that research in this area should explore areas that help deepen our understanding of individuals within the transgender community in ways that will provide more clinical utility. As researchers who also identify as clinical therapists, it was essential that our research have clinical utility. We sought to explore variables that are often seen in the therapy room, Therefore, we suggest that research using variables that include an individual's cognitive evaluations within the context of their interpersonal world to be most clinically relevant, particularly when these variables speak to how individuals' perceive SWL. Clinicians who are developing an individualized treatment plan for their transgender clients can benefit from this research as they develop trans-affirmative assessment questions or relevant areas to intervene.

Specifically, those clients who are balancing the intersectionality of two stigmatized identities would benefit from psychotherapy that integrates information on how SSC and IH impacts their life satisfaction. This therapeutic approach is consistent with World Professional Association for Transgender Health's Standards of Care who recommend that the goals of psychotherapy with transgender clients should "find ways to maximize a person's overall psychological well-being, quality of life, and self-fulfillment" (Coleman et al., 2012, p. 29). Referral routes for clients who seek peer support and an affirmative community could be tailored for those clients whose concerns are related to $\mathrm{SSC}$ and/or $\mathrm{IH}$.

Furthermore, the World Professional Association for Transgender Health's Standards of Care recommended that mental health practitioners use information to advocate on behalf of their clients (Coleman et al., 2012). This is particularly useful in workplace and educational environments where stigma can have a lasting impact on a transgender person's ability to pursue careers or life goals. This study adds to the literature that supports mental health professionals and provides necessary information for allies and advocates who seek to provide sustained SWL for transgender people. 


\section{References}

Ainsworth, T. A., \& Spiegel, J. H. (2010). Quality of life of individuals with and without facial feminization surgery or gender reassignment surgery. Quality of Life Research: An International Journal of Quality of Life Aspects of Treatment, Care and Rehabilitation, 19, 1019-1024. doi:10.1007/s11136-010-9668-7

American Psychological Association. (2015). Guidelines for psychological practice with transgender and gender nonconforming people. Retrieved from http://www.apa.org/practice/guidelines/transgender.pdf

Andrinopoulos, K., Hembling, J., Guardado, M. E., de Maria Hernandez, F., Nieto, A. I., \& Melendes, G. (2015). Evidence of the negative effect of sexual minority stigma on HIV testing among MSM and transgender women in San Salvador, El Salvador. AIDS and Behavior, 19, 60-71. doi:10.1007/s10461-014-0813-0

Aubrey, J. S. (2007). The impact of sexually objectifying media exposure on negative body emotions and sexual self-perceptions: Investigating the mediating role of body self-consciousness. Mass Communication \& Society, 10, 1-23. doi:10.1080/15205430709337002

Bariola, E., Lyons, A., Leonard, W., Pitts, M., Badcock, P., \& Couch, M., (2015). Demographic and psychosocial factors associated with psychological distress and resilience among transgender individuals. American Journal of Public Health, 105, 2109-2116. doi:10.2105/AJPH.2015.302763

Bauer, G. R., \& Hammond, R., (2015). Toward a broader conceptualization of trans women's sexual health. The Canadian Journal of Human Sexuality. 24, 1-11. doi:10.3138/cjhs.24.1-CO1

Beemyn, B. (2003). Serving the needs of transgender college students. Journal of Gay \& Lesbian Issues in Education, 1, 33-50. doi:10.1300/J367v01n01_03

Birnbaum, G. E., Reis, H. T., Mikulincer, M., Gillath, O., \& Orpaz, A. (2006). When sex is more than just sex: Attachment orientations, sexual experience, and relationship quality. Journal of Personality and Social Psychology, 91, 929-943. doi:10.1037/0022-3514.91.5.929

Bockting, W., Benner, A., \& Coleman, E. (2009). Gay and bisexual identity development among female-to-male transsexuals in North America: Emergence of a transgender sexuality. Archives of Sexual Behavior, 38, 688-701.

Breakwell, G. M., \& Millward, L. J. (1997). Sexual self-concept and sexual risk-taking. Journal of Adolescence, 20, 29-41. doi:10.1006/jado.1996.0062

Breslow, A. S., Brewster, M. E., Velez, B. L., Wong, S., Geiger, E., \& Soderstrom, B. (2015). Resilience and collective action: Exploring buffers against minority stress for transgender individuals. Psychology of Sexual Orientation and Gender Diversity, 2, 253-265. doi:10.1037/sgd0000117

Bryce, D. M. (2013). Predicting men's relationship satisfaction with men through internalized homonegativity and restricted emotionality (Doctoral dissertation). Retrieved from Dissertation Abstracts International. http://search.proquest.com/docview/1286855595

Carroll, L., \& Gilroy, P. J. (2002). Transgender issues in counselor preparation. Counselor Education and Supervision, 41, 233-242. doi:10.1002/j.1556-6978.2002.tb01286.x 
Cohen, J. (1988). Statistical power analysis for the behavioral sciences (2nd ed.). Mahwah, NJ: Lawrence Erlbaum.

Coleman, E., Bockting, W., Botzer, M., Cohen-Kettenis, P., DeCuypere, G., Feldman, J., ... Zucker, K. (2012). Standards of care for the health of transsexual, transgender, and gendernonconforming people, version 7. International Journal of Transgenderism, 13, 165-232. doi:10.1080/15532739.2011.700873

Costa, P. A., Pereira, H., \& Leal, I. (2013). Internalized homonegativity, disclosure, and acceptance of sexual orientation in a sample of Portuguese gay and bisexual men, and lesbian and bisexual women. Journal of Bisexuality, 13, 229-244. doi:10.1080/15299716.2013.782481

DeNeve, K. M., \& Cooper, H. (1998). The happy personality: a meta-analysis of 137 personality traits and subjective well-being. Psychological Bulletin, 124, 197-229. doi:10.1037/00332909.124.2.197

Deutsch, A. R. (2012). A test of a conceptual model of sexual self-concept and its relation to other dimensions of sexuality (Doctoral dissertation). Retrieved from Digital Commons at University of Nebraska-Lincoln. (Paper 48)

Deutsch, A. R., Hoffman, L., \& Wilcox, B. L. (2014). Sexual self-concept: Testing a hypothetical model for men and women. Journal of Sex Research, 51, 37-41. doi:10.1080/00224499.2013.805315

Diaz, R. M., Ayala, G., Bein, E., Henne, J., \& Marin, B. V. (2001). The impact of homophobia, poverty, and racism on the mental health of gay and bisexual Latino men: Findings from 3 U.S. cities. American Journal of Public Health, 91, 927-932. doi:10.2105/AJPH.91.6.927

Diener, E. D., Emmons, R. A., Larsen, R. J., \& Griffin, S. (1985). The Satisfaction With Life Scale. Journal of Personality Assessment, 49, 71-75. doi:10.1207/s15327752jpa4901_13

Diener, E., Oishi, S., \& Lucas, R. E. (2003). Personality, culture, and subjective well-being: Emotional and cognitive evaluations of life. Annual Review of Psychology, 54, 403-425. doi:10.1146/annurev.psych.54.101601.145056

Diener, E. D., \& Ryan, K. (2009). Subjective well-being: A general overview. South African Journal of Psychology, 39, 391-406. doi:10.1177/008124630903900402

DiFulvio, G. T. (2015). Experiencing violence and enacting resilience: The case story of a transgender youth. Violence Against Women, 21, 1385-1405. doi:10.1177/1077801214545022

Donald, C., \& Ehrenfeld, J. M. (2015). The opportunity for medical systems to reduce health disparities among lesbian, gay, bisexual, transgender and intersex patients. Journal of Medical Systems, 39, 1-7. doi:10.1007/s10916-015-0355-7

Edwards, K. M., \& Sylaska, K. M. (2013). The perpetration of intimate partner violence among LGBTQ college youth: The role of minority stress. Journal of Youth and Adolescence, 42, 1721-1731. doi:10.1007/s10964-012-9880-6

Elliott, A. N., \& O'Donohue, W. T. (1997). The effects of anxiety and distraction on sexual arousal in a nonclinical sample of heterosexual women. Archives of Sexual Behavior, 26, 607-624. doi:10.1023/A:1024524326105

Erich, S., Tittsworth, J., Dykes, J., \& Cabuses, C. (2008). Family relationships and their correlations with transsexual well-being. Journal of GLBT Family Studies, 4, 419-432. doi:10.1080/15504280802126141 
Fingerhut, A. W., Peplau, A. P., \& Ghavami, N. (2005). A dual-identity framework for understanding lesbian experience. Psychology of Women Quarterly, 29, 129-139. doi:10.1111/j.14716402.2005.00175.x

Frost, D. M., \& Meyer, I. H. (2009). Internalized homophobia and relationship quality among lesbians, gay men, and bisexuals. Journal of Counseling Psychology, 56, 97-109. doi:10.1037/a0012844

Gagné, P., Tewksbury, R., \& McGaughey, D. (1997). Coming out and crossing over identity formation and proclamation in a transgender community. Gender \& Society, 11, 478-508. doi:10.1177/089124397011004006

Garcia, L. T. (1999). The certainty of the sexual self-concept. Canadian Journal of Human Sexuality, 8, 263-270.

Garnets, L., \& Kimmel, D. (1993). Psychological perspectives on lesbian and gay male experiences. New York, NY: Columbia University Press.

Giordano, F. G., \& Rush, L. C. (2010). Self-esteem and sexuality: An exploration of differentiation and attachment. In M. H. Guindon (Ed.), Self-esteem across the lifespan: Issues and interventions (pp. 205-218). New York, NY: Routledge/Taylor \& Francis Group.

Gorin-Lazard, A., Baumstarck, K., Boyer, L., Maquigneau, A., Gebleux, S., Penochet, J.-C., ... Bonierbale, M. (2012). Is hormonal therapy associated with better quality of life in transsexuals? A cross-sectional study. The Journal of Sexual Medicine, 9, 531-541. doi:10.1111/j.1743-6109.2011.02564.x

Graham, L. F., Crissman, H. P., Tocco, J., Hughes, L. A., Snow, R. C., \& Padilla, M. B. (2014). Interpersonal relationships and social support in transitioning narratives of black transgender women in Detroit. International Journal of Transgenderism, 15, 100-113. doi:10.1080/15532739.2014.937042

Grant, J. M., Mottet, L., Tanis, J. E., Harrison, J., Herman, J., \& Keisling, M. (2011). Injustice at every turn: A report of the National Transgender Discrimination Survey. Washington, DC: National Center for Transgender Equality.

Greene, B. (1994). Ethnic-minority lesbians and gay men: Mental health and treatment issues. Journal of Consulting and Clinical Psychology, 62, 243-251. doi:10.1037/0022-006X.62.2.243

Hays, R. D., Sherbourne, C. D., \& Mazel, R. M. (1995). User's manual for the Medical Outcomes Study (MOS) core measures of health-related quality of life. Santa Monica, CA: RAND.

Hensel, D. J., Fortenberry, J. D., O’Sullivan, L. F., \& Orr, D. P. (2011). The developmental association of sexual self-concept with sexual behavior among adolescent women. Journal of Adolescence, 34, 675-684. doi:10.1016/j.adolescence.2010.09.005

Herek, G. M. (2004). Beyond "homophobia": Thinking about sexual prejudice and stigma in the twenty-first century. Sexuality Research \& Social Policy, 1, 6-24. doi:10.1525/srsp.2004.1.2.6

Human Rights Campaign. (2016). Glossary of terms. Retrieved from www.hrc.org/resources/glossaryof-terms

Jacobs, R. J., Fernandez, M. I., Ownby, R. L., Bowen, G. S., Hardigan, P. C., \& Michael, K. N. (2010). Factors associated with risk for unprotected receptive and insertive anal intercourse in men aged 40 and older who have sex with men. AIDS Care, 22, 1204-1211. doi:10.1080/09540121003615137 
Jordan, K. M., \& Deluty, R. H. (2000). Social support, coming out, and relationship satisfaction in lesbian couples. Journal of Lesbian Studies, 4, 145-164. doi:10.1300/J155v04n01_09

Kappler, S. Hancock, K. A., \& Plante, T. G. (2013). Roman Catholic gay priests: Internalized homophobia, sexual identity and psychological well-being. Pastoral Psychology, 62, 805-826. doi:10.1007/s11089-012-0505-5

King, M., Semlyen, J., Tai, S. S., Killaspy, H., Osborn, D., Popelyuk, D., \& Nazareth, I. (2008). A systematic review of mental disorder, suicide, and deliberate self-harm in lesbian, gay and bisexual people. BMC Psychiatry, 8, 1-17. doi:10.1186/1471-244X-8-70

King, L. A., \& Smith, N. G. (2004). Gay and straight possible selves: Goals, identity, subjective wellbeing, and personality development. Journal of Personality, 72, 967-994. doi:10.1111/j.00223506.2004.00287

Lawton, M. P. (1991). A multidimensional view of quality of life in frail elders. In J. E. Birren, J. E. Lubben, J. C. Rowe \& D. E. Deutchman (Eds.), The concept and measurement of quality of life in the frail elderly (pp. 3-27). San Diego, CA: Academic Press.

Legate, N., Ryan, R. M., \& Weinstein, N. (2012). Is coming out always a "good thing"? Exploring the relations of autonomy support, outness, and wellness for lesbian, gay, and bisexual individuals. Social Psychological and Personality Science, 3, 145-152. doi:10.1177/1948550611411929

Lenning, E., \& Buist, C. L. (2013). Social, psychological and economic challenges faced by transgender individuals and their significant others: Gaining insight through personal narratives. Culture, Health \& Sexuality, 15, 44-57. doi:10.1080/13691058.2012.738431:

Lombardi, E. L., Wilchins, R. A., Priesing, D., \& Malouf, D. (2002). Gender violence: Transgender experiences with violence and discrimination. Journal of Homosexuality, 42, 89-101. doi:10.1300/J082v42n01_05

Mayers, K. S., Heller, D. K., \& Heller, J. A. (2003). Damaged sexual self-esteem: A kind of disability. Sexuality \& Disability, 21, 269-282. doi:10.1023/B:SEDI.0000010069.08844.04

Meier, S. C., \& Labuski, C. M. (2013). The demographics of the transgender population. In A. K. Baumle (Ed.), International handbook on the demography of sexuality (pp. 289-327). New York, NY: Springer Science \& Business Media. doi:10.1007/978-94-007-5512-3

Ménard, A. D., \& Offman, A. (2009). The interrelationships between sexual self-esteem, sexual assertiveness and sexual satisfaction. Canadian Journal of Human Sexuality, 18, 35.

Miller, P. G., Hyder, S., Zinkiewicz, L., Droste, N., \& Harris, J. B. (2014). Comparing subjective wellbeing and health-related quality of life of Australian drug users in treatment in regional and rural Victoria. Drug and alcohol review, 33, 651-657. doi:10.1111/dar.12124

Mizock, L., \& Hopwood, R. (2016). Conflation and interdependence in the intersection of gender and sexuality among transgender individuals. Psychology of Sexual Orientation and Gender Diversity, 3, 93-103. doi:10.1037/sgd0000157

Mizock, L., \& Lewis, T. K. (2008). Trauma in transgender populations: Risk, resilience, and clinical care. Journal of Emotional Abuse, 8, 335-354. doi:10.1080/10926790802262523

Mohr, J., \& Fassinger, R. (2000). Measuring dimensions of lesbian and gay male experience. Measurement and Evaluation in Counseling and Development, 33, 66-90. 
Morrison, M. A. (2012). Psychological health correlates of perceived discrimination among Canadian gay men and lesbian women. Canadian Journal of Community Mental Health, 30, 81-98. doi:10.7870/cjcmh-2011-0018

Motmans, J., Meier, P., Ponnet, K., \& T'Sjoen, G. (2012). Female and male transgender quality of life: Socioeconomic and medical differences. The Journal of Sexual Medicine, 9, 743-750. doi:10.1111/j.1743-6109.2011.02569.x

Newfield, E., Hart, S., Dibble, S., \& Kohler, L. (2006). Female-to-male transgender quality of life. Quality of Life Research: An International Journal of Quality of Life Aspects of Treatment, Care and Rehabilitation, 15, 1447-1457. doi:10.1007/s11136-006-0002-3

O'Sullivan, L. F., Meyer-Bahlburg, H. F. L., \& McKeague, I. W., (2006). The development of the sexual self-concept inventory for early adolescent girls. Psychology of Women Quarterly. 30,139-149. doi:10.1111/j.1471-6402.2006.00277

Palace, E. M., \& Gorzalka, B. B. (1990). The enhancing effects of anxiety on arousal in sexually dysfunctional and functional women. Journal of Abnormal Psychology, 99, 403-411. doi:10.1037/0021-843X.99.4.403

Palgi, Y., \& Shmotkin, D. (2010). The predicament of time near the end of life: Time perspective trajectories of life satisfaction among the old-old. Aging \& Mental Health, 14, 577-586. doi:10.1080/13607860903483086

Peitzmeier, S. M., Yazin, F., Stephenson, R., Wirtz, A. L., Delegchoimbol, A., Dorjgotov, M., \& Baral, S., (2015). Sexual violence against men who have sex with men and transgender women in Mongolia: A mixed-methods study of scope and consequences. PLoS ONE 10, e0139320. doi:10.1371/journal.pone.0139320

Peterson, C., Park, N., \& Seligman, M. E. P. (2005). Orientations to happiness and life satisfaction: The full life versus the empty life. Journal of Happiness Studies, 6, 25-41. doi:10.1007/s10902-004-1278-z

Pflum, S. R., Testa, R. J., Balsam, K. F., Goldblum, P. B., \& Bongar, B. (2015). Social support, trans community connectedness, and mental health symptoms among transgender and gender nonconforming adults. Psychology of Sexual Orientation and Gender Diversity, 2, 281-286. doi:10.1037/sgd0000122

Ross, M. W., Kajubi, P., Mandel, J. S., McFarland, W., \& Raymond, H. F. (2013). Internalized homonegativity/homophobia is associated with HIV-risk behaviours among Ugandan gay and bisexual men. International Journal of STD \& AIDS, 24, 409-413. doi:10.1177/0956462412472793

Rostosky, S. S., Dekhtyar, O., Cupp, P. K., \& Anderman, E. M. (2008). Sexual self-concept and sexual self-efficacy in adolescents: A possible clue to promoting sexual health? Journal of Sex Research, 45, 277-286. doi:10.1080/00224490802204480

Safren, S. A., \& Pantalone, D. W. (2006). Social anxiety and barriers to resilience among lesbian, gay, and bisexual adolescents. In A. M. Omoto \& H. S. Kurtzman (Eds.), Contemporary perspectives on lesbian, gay, and bisexual psychology (pp. 55-71). Washington, DC: American Psychological Association. doi:10.1037/11261-003

Seligman, M. (2002). Authentic happiness: Using the new positive psychology to realize your potential for lasting fulfillment. New York, NY: Simon \& Schuster. 
Shahar, T. B. (2007). Happier: Learn the secrets to daily joy and lasting fulfillment. New York, NY: McGraw Hill.

Shepler, D. K., Johnson, K. P., \& Ho, M. A. (2015, August). Differences in satisfaction with life between LGB and heterosexual individuals. In D. K. Shepler (Chair), LGBT satisfaction with life: Findings and future directions. Symposium conducted at the 123rd annual Convention of the American Psychological Association, Toronto, Canada.

Simons, L., Schrager, S. M., Clark, L. F., Belzer, M., \& Olson, J. (2013). Parental support and mental health among transgender adolescents. Journal of Adolescent Health, 53, 791-793. doi:10.1016/j.jadohealth.2013.07.019

Singh, A. A. (2013). Transgender youth of color and resilience: Negotiating oppression and finding support. Sex Roles, 68, 690-702. doi:10.1007/s11199-012-0149-z

Smolenski, D. J., Stigler, M. H., Ross, M. W., \& Rosser, B. R. S. (2011). Direct and indirect associations between internalized homonegativity and high-risk sex. Archives of Sexual Behavior, 40, 785-792. doi:10.1007/s10508-010-9705-1

Snell, W. E., Jr., Fisher, T. D., \& Walters, A. S. (1993). The Multidimensional Sexuality Questionnaire: An objective self-report measure of psychological tendencies associated with human sexuality. Annals of Sex Research, 6, 27-55. doi:10.1007/BF00849744

Snell, W. E. (1998). The multidimensional sexual self-concept questionnaire. In C. M. Davis, W. L. Yarber, R. Bauserman, G. Schreer \& S. L Davis (Eds.), Handbook of sexuality-related measures (pp. 521-524).Thousand Oaks, CA: Sage.

Strain, J. D., \& Shuff, I. M. (2010). Psychological well-being and level of outness in a population of male-to-female transsexual women attending a national transgender conference. International Journal of Transgenderism,12, 230-240. doi:10.1080/15532739.2010.544231

Sutter, M., \& Perrin, P. B. (2016). Discrimination, mental health, and suicidal ideation among LGBTQ people of color. Journal of Counseling Psychology, 63, 98-105. doi:10.1037/cou0000126

van den Hout, M., \& Barlow, D. (2000). Attention, arousal and expectancies in anxiety and sexual disorders. Journal of Affective Disorders, 61, 241-256. doi:10.1016/S0165-0327(00)00341-4

Vickberg, S. M. J., \& Deaux, K. (2005). Measuring the dimensions of women's sexuality: The women's sexual self-concept scale. Sex Roles, 53, 361-369. doi:10.1007/s11199-005-6759-y

Wagner, G. J. (1998). Internalized Homophobia Scale. In C. M. Davis, W. L. Yarber, R. Bauserman, G. Schreer \& S. L Davis (Eds.), Handbook of sexuality-related measures (pp. 371-372). Thousand Oaks, CA: Sage.

Ware Jr., J. E., \& Sherbourne, C. D. (1992). The MOS 36-item short-form health survey (SF-36): I. Conceptual framework and item selection. Medical Care, 473-483.

Warner, L. R. (2008). A best practices guide to intersectional approaches in psychological research. Sex Roles, 59, 454-463. doi:10.1007/s11199-008-9504-5

Weyers, S., Monstrey, S., Hoebeke, P., De Cuypere, G., \& Gerris, J. (2008). Laparoscopic hysterectomy as the method of choice for hysterectomy in female-to-male gender dysphoric individuals. Gynecological Surgery, 5, 269-273. doi:10.1007/s10397-008-0386-x 
Wierckx, K., Van Caenegem, E., Elaut, E., Dedecker, D., Van de Peer, F., Toye, K., ... T’Sjoen, G. (2011). Quality of life and sexual health after sex reassignment surgery in transsexual men. The Journal of Sexual Medicine, 8, 3379-3388. doi:10.1111/j.1743-6109.2011.02348.x

Wilkerson, J. M., Smolenski, D. J., Brady, S. S., \& Rosser, B. R. S. (2012). Religiosity, internalized homonegativity and outness in Christian men who have sex with men. Sexual and Relationship Therapy, 27, 122-132. doi:10.1080/14681994.2012.698259

Winter, L. (1988). The role of sexual self-concept in the use of contraceptives. Family Planning Perspectives, 20, 123-127. doi:10.2307/2135700

Zeanah, P. D., \& Schwarz, J. C. (1996). Reliability and validity of the Sexual Self-Esteem Inventory for Women. Assessment, 3, 1-15. doi:10.1177/107319119600300101

The Journal of Social, Behavioral, and Health Sciences is an open-access, peer-reviewed, online interdisciplinary journal focusing on research findings that address contemporary national and international issues. Its objectives are to (a) encourage dialogue between scholars and practitioners in the social, behavioral, and health sciences that fosters the integration of research with practice; (b) promote innovative models of interdisciplinary collaboration among the social, behavioral, and health sciences that address complex social problems; and (c) inform the relationship between practice and research in the social, behavioral, and health sciences.

Walden University Publishing: http://www.publishing.waldenu.edu 